\title{
Exploring the Impact of Single-Nucleotide Polymorphisms on Translation
}

\author{
Francis Robert ${ }^{1}$ and Jerry Pelletier ${ }^{1,2,3 *}$ \\ ${ }^{1}$ Department of Biochemistry, McGill University, Montreal, QC, Canada, ${ }^{2}$ Department of Oncology, McGill University, \\ Montreal, QC, Canada, ${ }^{3}$ Rosalind and Morris Goodman Cancer Research Centre, McGill University, Montreal, QC, Canada
}

\section{OPEN ACCESS}

Edited by:

Maritza Jaramillo,

University of Quebec, Canada

Reviewed by:

Jun Yasuda,

Miyagi Cancer Center, Japan

Eric Londin,

Thomas Jefferson University, United States

Tommy Alain,

University of Ottawa, Canada

*Correspondence:

Jerry Pelletier

jerry.pelletier@mcgill.ca

Specialty section:

This article was submitted to

$R N A$,

a section of the journal

Frontiers in Genetics

Received: 13 August 2018 Accepted: 10 October 2018 Published: 30 October 2018

Citation:

Robert $F$ and Pelletier J (2018) Exploring the Impact

of Single-Nucleotide Polymorphisms on Translation. Front. Genet. 9:507.

doi: 10.3389/fgene.2018.00507
Over the past 15 years, sequencing of the human genome and The Cancer Genome Atlas (TCGA) project have led to comprehensive lists of single-nucleotide polymorphisms (SNPs) and gene mutations across a large number of human samples. However, our ability to predict the functional impact of SNPs and mutations on gene expression is still in its infancy. Here, we provide key examples to help understand how mutations present in genes can affect translational output.

Keywords: translation initiation, elF4F, ribosome recruitment, SNP, genetic variant

\section{SEQUENCE VARIATION AND GENE EXPRESSION}

In the last two decades, advances in genome sequencing has provided unprecedented access to the human genome landscape and enabled documentation of sequence variations among individuals. Humans share $99.5 \%$ identity at the genomic sequence level implying that the resulting phenotypic diversity stems from the remaining $0.5 \%$ difference as well as epigenetic modifications. Sequence differences arise due to the presence of short and variable number tandem repeats, insertion or deletion polymorphisms, and single-nucleotide polymorphisms (SNPs) (Mccarroll et al., 2006; Orr and Chanock, 2008). Among SNPs, transitions (A $\leftrightarrow \mathrm{G}$ or $\mathrm{C} \leftrightarrow \mathrm{T}$ ) are more prevalent than transversions ( $\mathrm{A} \leftrightarrow \mathrm{C}$ or $\mathrm{T}$; and $\mathrm{G} \leftrightarrow \mathrm{C}$ or $\mathrm{T}$ ). There are at least 10 million SNPs within the genome, occurring approximately every 100-300 base pairs and with an allele frequency greater than $1 \%$, making these by far the most common variant type in the human genome (Risch, 2000; Lander et al., 2001; Orr and Chanock, 2008). Recently, there has been a bloom in genome-wide association studies (GWAS) where the prevalence of specific SNPs is linked to phenotypes or disease (Srinivasan et al., 2016). As well, The Cancer Genome Atlas (TCGA) has identified sequence variations between tumor and normal cells and the current challenge is distinguishing between those mutations that exert effects on gene expression to drive tumor evolution versus irrelevant passenger mutations.

Mutations have the potential to alter all steps of gene expression depending on their genomic location. When present within transcriptional regulatory elements, they can affect mRNA expression. When arising in genes, SNPs can impact on mRNA splicing, nucleo-cytoplasmic export, stability, and translation. When present within a coding sequence and leading to an amino acid change (referred to as a non-synonymous SNP or mutation), they can modify the protein's activity. If the mutation is synonymous (i.e., does not change the nature of the amino acid), then translation rates or mRNA half-life may be affected. If the mutation causes a premature stop codon, this can lead to the production of a truncated protein product or a near-null phenotype due to nonsense mediated decay (Mendell and Dietz, 2001; Nicholson et al., 2010). The Encyclopedia of DNA 
Elements $(\mathrm{ENCODE})^{1}$ project aims to identify and catalog functional elements in the human genome and has been quite useful in understanding the potential impact that sequence variations exert on gene expression (Consortium, 2012). However, the functional consequences of sequence variants that occur within mRNA $5^{\prime}$ leader [i.e., the region upstream of the initiator codon of the main open reading frame (ORF)] and $3^{\prime}$ untranslated regions (UTRs) (i.e., the region downstream of the major ORF stop codon) are not always immediately obvious and often not characterized. Here, we provide some thoughts on how such variants could affect mRNA translation efficiency. We highlight the individual steps of translation that sequence variants can affect, citing choice examples when appropriate and these are summarized in Table 1.

\section{AN OVERVIEW OF EIF4F-DEPENDENT RIBOSOME RECRUITMENT}

Mammalian protein synthesis is predominantly regulated at the step of translation initiation, with the rate-limiting step being the recruitment of ribosomes to mRNAs (Figure 1A; Sonenberg and Hinnebusch, 2009). The key mediator of this step is the eIF4F complex. The eIF4E subunit binds to the mRNA cap structure present on all eukaryotic cytoplasmic mRNAs. The eIF4G component has RNA binding domains and stabilizes the eIF4E: cap interaction (Marcotrigiano et al., 2001; Yanagiya et al., 2009). RNA structural elements are resolved by the eIF4A DEADbox RNA helicase in conjunction with RNA binding proteins, eIF4B and/or eIF4H (Figure 1A). The 43S pre-initiation complex (40S ribosome and associated factors) (PIC) is then recruited to the mRNA template via bridging interactions between eIF4G and ribosome-bound eIF3 (Sonenberg and Hinnebusch, 2009). This mode of initiation is referred to as cap- or eIF4E-dependent. The requirement for eIF4F by $\mathrm{mRNAs}$ to recruit ribosomes differs and appears to scale as a consequence of $5^{\prime}$ leader secondary structure (Pickering and Willis, 2005; Bitterman and Polunovsky, 2015; Hinnebusch et al., 2016). Since eIF4E is thought to be limiting for translation, mRNAs must compete for access to eIF4F and those with structural barriers in their $5^{\prime}$ leader region are at a disadvantage (Pelletier and Sonenberg, 1985; Babendure et al., 2006). Hence, altering the secondary structure landscape within the mRNA $5^{\prime}$ leader region can significantly impact on translational efficiency by affecting ribosome recruitment rates (Pelletier et al., 2015). Once bound, the 43S PIC scans the mRNA $5^{\prime}$ leader region in search of an initiation codon.

A second mechanism by which the 43 S PIC can be recruited to mRNA templates is through direct internal binding within the $5^{\prime}$ leader region to an internal ribosome entry site (IRES), obviating the requirement for the cap structure. Best characterized among these are the viral IRESes and these have been stratified in four classes, based on structural similarities, initiation factor and/or IRES trans-acting factor requirements (Mailliot and Martin, 2018). Some exceptional IRESes, such as the cricket paralysis

${ }^{1}$ https://www.encodeproject.org/ virus IRES, bypass the need for any initiation factors and can directly bind to the ribosome.

The discovery and characterization of IRESes in cellular mRNAs is of significant interest since they have been implicated in allowing translation to proceed under conditions when capdependent translation is impaired, such as stress, apoptosis, nutrient limitation, and mitosis (Komar and Hatzoglou, 2015). Cellular IRES function is therefore thought to be important for allowing rapid adaptation to a quickly changing environment, with selective translational effects being the outcome. Influences of SNPs on cellular IRESes activity could affect response to stress such as hypoxia, heat shock, toxins, or drugs (chemotherapy). As well, mutations in cellular IRESes could lead to aberrant translational responses to drive a number of pathological disorders, ranging from autoimmune disease, neurodegeneration, and cancer (Holcik and Sonenberg, 2005).

\section{CHANGES IN SECONDARY STRUCTURE AFFECTING TRANSLATIONAL OUTPUT}

By impeding eIF4F-cap interactions or ribosome scanning, structural features (e.g., stem-loops, RNA-protein complexes, G-quadruplexes) can act as barriers to translation initiation and negatively impact translational efficiency (Pelletier and Sonenberg, 1985; Babendure et al., 2006). A study by Shen et al. (1999) was one of the first to document the extensive impact that SNPs can have on mRNA secondary structure (Table 1). Analysis of two SNPs within the coding regions of mRNAs encoding alanyl tRNA synthetase and replication protein A uncovered allele-specific structural features that impacted on sequence accessibility. Evidence that such changes can affect translational output was provided by a study assessing the influence of G-quadruplex structures present in $5^{\prime}$ leader regions on translation (Beaudoin and Perreault, 2010). A SNP ( $G$ to $C$ change) was identified at position 7 of a G-quadruplex (a critical region for G-quadruplex formation) within the $5^{\prime}$ leader of the AASDHPPT (aminoadipatesemialdehyde dehydrogenase-phosphopantetheinyl transferase) mRNA (Beaudoin and Perreault, 2010). Biophysical experiments showed that G-quadruplex formation was disrupted and this was associated with 1.5-fold increase in protein levels in cells, with no effect on mRNA levels (Beaudoin and Perreault, 2010). These experiments indicate that point mutations in $5^{\prime}$ leader regions that alter secondary structure can impact on translational output.

Secondary structure immediately downstream of the AUG can also affect translational output. For example, an A to G synonymous SNP at a Leu codon, present in the coding region of the catechol-O-methyltransferase (COMT) mRNA, was identified in subjects with high pain sensitivity and at greater risk of developing temporomandibular joint disorder (Diatchenko et al., 2005; Nackley et al., 2006). The COMT protein is responsible for catecholamine degradation and is a regulator of pain perception. In humans, three major haplotypes are formed by four SNPs at the COMT locus: one located in the promoter and three in the coding region [two synonymous at his ${ }^{62}$ his $(\mathrm{C} / \mathrm{T})$ and $l e u^{136} l e u(\mathrm{C} / \mathrm{G})$ and one non-synonymous val $^{158}$ met 
TABLE 1 | Summary of the SNPs described in this study.

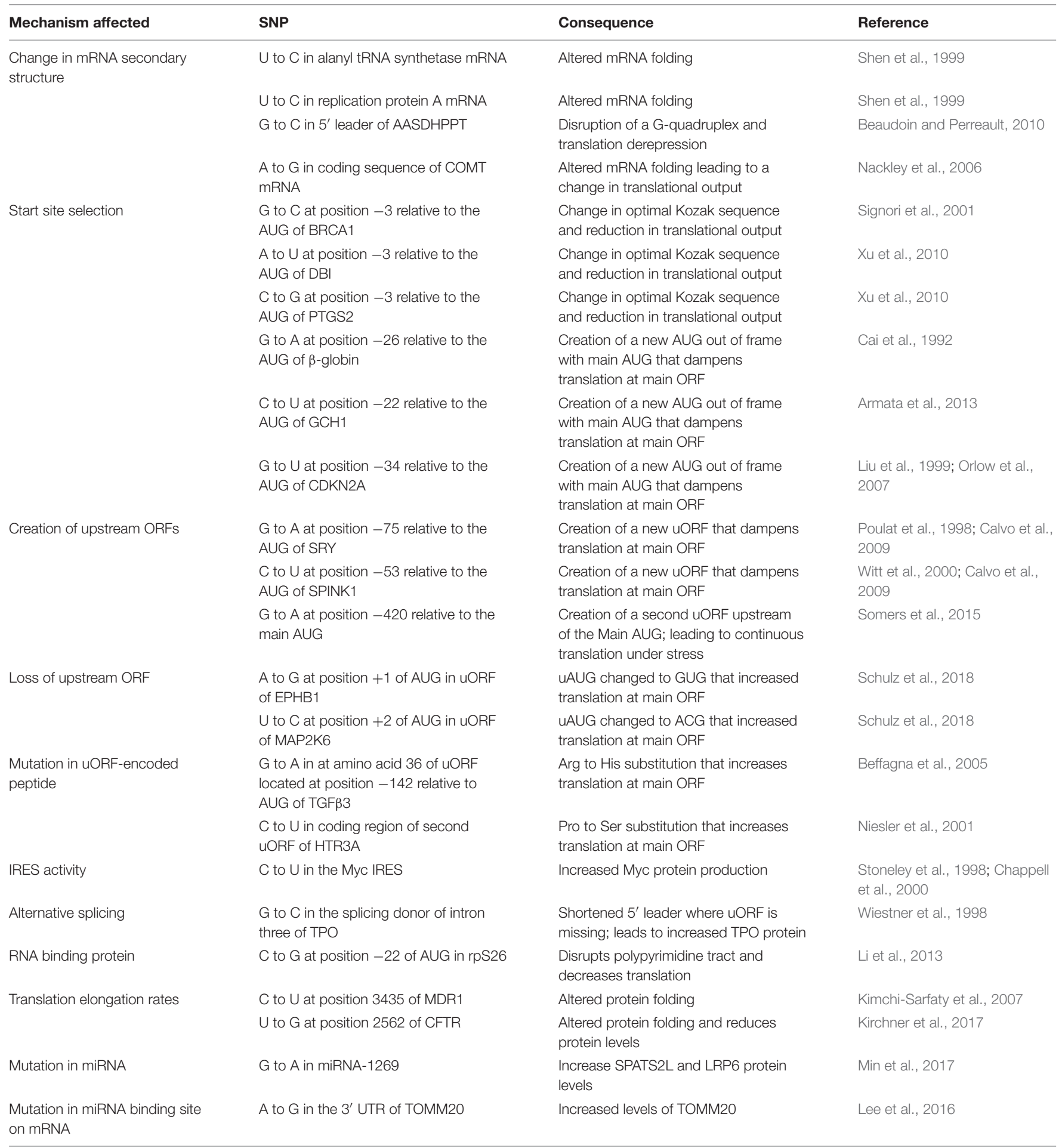

(A/G)] (Nackley et al., 2006). It was reported that the major COMT haplotypes varied with respect to local mRNA secondary structure with the most stable structure associated with the lowest levels of protein production (Nackley et al., 2006). Site-directed mutagenesis disrupting the structural element caused an increase in protein production. The authors did not, however, directly assess the effect of the different haplotype sequences on mRNA translation rates.

Conversely, secondary structure can also act to increase start codon recognition when appropriately located downstream of initiation codons - an effect presumably due to the slowing of scanning ribosomes and increased codon sampling time 
(Kozak, 1991). Hence, sequence changes that increase the formation of structure in the AUG downstream proximal region could increase AUG utilization rates.

\section{5' LEADER SEQUENCE VARIATION AND START SITE SELECTION}

\section{SNPs Affect Start Codon Recognition}

The mechanism by which 43 S PICs locate an initiation codon has consequences on how SNPs that generate new, or remove existing, start codons affect translation initiation. The sequence context of an initiation codon dictates the efficiency by which it is recognized by scanning 43S PICs (Figure 1B). The optimal context is A/GxxAUGg, referred to as the Kozak consensus sequence, with the -3 purine (relative to the A of the AUG) being the most important determinant (Kozak, 1986, 1987a). Mutations that change this context are predicted to affect start site selection efficiency.

There are many examples of mutations that alter the AUG sequence context to impact on translational efficiency. One such example is the description of a mutation within the BRCA1 gene in a 35 years old patient converting a $G$ to $C$ at the -3 position relative to the BRCA1 AUG initiation codon (Signori et al., 2001). This mutation changes an optimal purine to a less favorable pyrimidine and has been linked to sporadic breast and ovarian cancers (Hall et al., 1990; Szabo and King, 1995). In vitro and in vivo expression studies of reporter mRNAs harboring the $\mathrm{C}$ allele showed a $30-50 \%$ decrease in protein expression compared to control mRNAs harboring the G allele. As well, the transcript carrying the $G$ allele was associated with heavier polysomes (and hence elevated translation rates) compared to the $\mathrm{C}$ allele containing mRNA.

The NCBI SNP database has been mined for the presence of variants spanning AUG initiation codons, with a focus on the -3 and +4 positions (Xu et al., 2010). This study identified SNPs in $>45$ genes that occurred at one of these two critical positions and could thus potentially affect AUG utilization. The variants of two genes were tested by transfection of reporter constructs into cells and revealed that mRNAs harboring SNPs with "weaker" or "stronger" Kozak consensus sequence produced reduced or elevated protein levels, respectively (Xu et al., 2010). No differences in mRNA levels were noted.

\section{SNPs Creating an In-Frame uAUG}

Mutations that generate start codons upstream, and in frame with, the major initiation codon of an open reading frame will "catch" some scanning 43S PICs and redirect protein synthesis to the new start site to produce $\mathrm{N}$-terminal extended protein products (Figure 1B, see "In-frame uAUG"). The efficiency with which this is achieved is dictated, in part, by the context surrounding the new initiation codon.

One bioinformatics tool which has been developed for categorizing effects of variants on genome function is SnpEff (Cingolani et al., 2012). This tool annotates variants based on genomic locations to include intronic, untranslated region, splice site, intergenic, non-synonymous coding, etc...
(Cingolani et al., 2012). Among the effects listed by SnpEff are changes in initiation codons (AUG and the less common CUG and UUG codons) that occur in the $5^{\prime}$ leader region. Of 297 SNPs that generated a new translation initiation codon in the $5^{\prime}$ leader region when comparing two Drosophila melanogaster strains, $\sim 25 \%$ were in the same reading frame as the major ORF (Cingolani et al., 2012) and would produce N-terminally extended polypeptides.

\section{SNPs Creating an uORF Out-of-Frame With the Major ORF}

If a mutation generates a new start codon out-of-frame with the major ORF AUG, some 43S PICs may initiate at the new upstream (u) ORF and by-pass the major ORF, resulting in a decrease in protein production from the major ORF-encoded product (Figure 1B and Table 1). The extent of re-routing will depend, in part, on the context of the novel initiation codon as well as AUG proximal secondary structure (Kozak, 1991; Barbosa et al., 2013).

As an example of such a scenario, a germline mutation in the $\beta$-globin gene $26 \mathrm{nt}$ upstream of the initiator AUG codon leads to the creation of a new, out-of-frame uAUG (Oner et al., 1991; Cai et al., 1992). This uAUG is in a favorable sequence context ( $A$ in the -3 position) and initiation at this $\mathrm{uAUG}$ shunts ribosomes pass the authentic AUG, reducing $\beta$-globin production, and leading to $\beta$-thalassemia. Whether or not mRNA stability is affected by a particular $5^{\prime}$ leader mutation and this also contributes to the phenotype needs to be carefully assessed.

A similar scenario has been documented in the GTP cyclohydrolase 1 gene (GCH1) in which heterozygous mutations are associated with Dopa-responsive dystonia (DRD) (Armata et al., 2013). Here, a germline $\mathrm{C}$ to $\mathrm{T}$ transition $22 \mathrm{nt}$ upstream of the translation start site generates a novel start codon that is out-of-frame with the downstream GCH1 AUG codon and results in reduced GCH1 production (Armata et al., 2013). It will be important to extend these results to: (i) formally demonstrate that the $\mathrm{C}$ to $\mathrm{T}$ transition leads to translation of the newly created uORF (an assessment that can be made by ribosome footprinting) and (ii) demonstrate that the $\mathrm{C}$ to $\mathrm{T}$ alteration leads to changes on endogenous $\mathrm{GCH} 1$ protein output.

The impact that this class of mutations can have on tumor biology is significant and is exemplified by the identification of a germline mutation in the CDKN2A tumor suppressor gene mapping 34 nucleotides upstream of the normal start site (Liu et al., 1999; Orlow et al., 2007). In this case, a G to T mutation creates a novel initiation codon residing in a favorable context but out-of-frame with the CDKN2A AUG. The T allele thus generates an mRNA that produces less $C D K N 2 A$ and substantially increases the risk of melanoma in carriers (Liu et al., 1999; Orlow et al., 2007).

\section{SNPs Creating an uORF Upstream of the Major ORF}

If the presence of a SNP leads to creation of a new uORF, this may impact gene expression by: (i) affecting re-initiation efficiency at the downstream major ORF, and (ii) generating a 


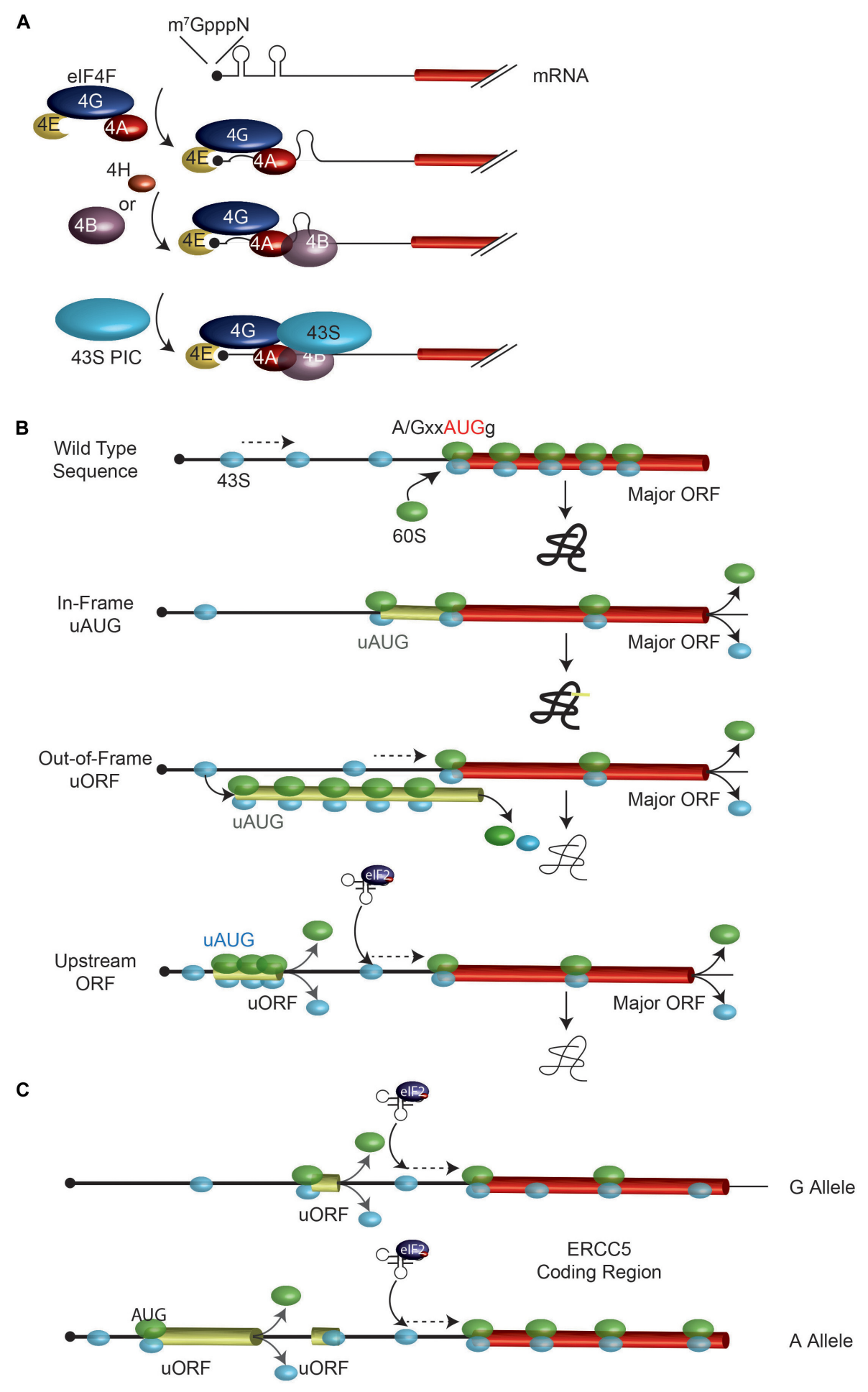

FIGURE 1 | Overview of ribosome recruitment and scanning. (A) Cap-dependent translation initiation. The elF4F complex, in conjunction with elF4B and elF4H, serves to prepare the mRNA for 435 ribosomal complex recruitment. (B) Impact of UAUGs and UORFs on ribosome scanning. When bound to the mRNA, the 43S PIC (in light blue) scans the mRNA in search for an initiator AUG. An AUG codon in a favorable context is efficiently recognized by the scanning 405 subunit, at which point a 605 subunit will join and elongation begins. Mutations creating novel UAUGs or UORFs will influence the frequency of ribosomes that initiate at the major ORF AUG codon. The position of an UORF, relative to the major AUG codon is important in determining major AUG utilization since the distance from the uORF stop codon and the major AUG dictates the time it will take for a ribosome to re-acquire a elF2*GTP*Met-tRNA ternary complex. (C) A G/A SNP in the ERCC5 mRNA $5^{\prime}$ leader region controls expression and response to stress. The A allele containing mRNA has an additional uORF which allows for more efficient ERCC5 main ORF translation under situations when elF2 $\alpha$ is phosphorylated. See text for details. 
novel peptide encoded by the uORF (Barbosa et al., 2013). The precise mechanism of how $40 \mathrm{~S}$ ribosomes are able to resume protein synthesis after having translated an uORF is not well defined but is related to the length of the uORF (the longer the uORF, the less efficient the re-initiation process) as well as the presence of structural barriers in the UORF (which reduces reinitiation potential) (Figure 1B; Kozak, 1987b; Abastado et al., 1991; Poyry et al., 2004). It is thought that initiation factors critical for re-initiation remain ribosome-bound for some time following commencement of elongation, but at some point are lost or ejected from the translating ribosome. If termination of translation occurs before these factors are lost, then that ribosome maintains its ability to reinitiate (Poyry et al., 2004). An analysis of 11,649 matched mRNA and protein measurements from four published mammalian studies have indicated that the presence of $\mathrm{uORF}$ s within the $5^{\prime}$ leader region is generally associated with reduced expression from the major ORF (Calvo et al., 2009).

The repressive nature of a newly created uORF can, in part, stem from the reduced efficiency associated with translation re-initiation compared to de novo, cap-dependent translation initiation. Calvo et al. (2009) undertook a search for ORFaltering nucleotide variants within 12 million SNPs present in $\mathrm{dbSNP}^{2}$. They found a number of novel and previously described polymorphisms predicted to create new, or remove existing, uORFs. For example, mutations within the $5^{\prime}$ leader region of the SRY (Poulat et al., 1998) and SPINK1 (Witt et al., 2000) mRNAs introduced novel uORFs upstream of the major ORF. Testing of reporters with different $5^{\prime}$ leaders showed that those harboring uORFs produce less major ORF protein compared to reporters expressing control, wild-type $5^{\prime}$ leader sequences. In general, the occurrence of a new uORF is associated with a $30-80 \%$ decrease in protein synthesis from the major ORF (Calvo et al., 2009).

Mutations that lead to the loss of an uORF can increase translation output. Analysis of $404 \mathrm{uORFs}$ present in the $5^{\prime}$ leaders of mRNAs encoding 83 tyrosine kinases and 49 other proto-oncogenes in 308 human malignancies uncovered uORF mutations in the EPHB1 and MAP2K6 genes (Schulz et al., 2018). In the case of $E P H B 1$, a mutation changed the only uAUG found in the $5^{\prime}$ leader to a GUG codon, while the sole uAUG of MAP2K6 was modified to an ACG codon. Both of the identified mutations lead to an increase in translational output from their respective mRNAs. This was complemented by a computational analysis of whole exome sequencing data from 464 colon cancers which revealed somatic mutations leading to the loss of $22 \mathrm{uORF}$ initiation and $31 \mathrm{uORF}$ termination codons (Schulz et al., 2018).

The presence of an UORF has also been shown to confer resistance to cisplatin exposure by facilitating translation of the major ORF encoded polypeptide under stress conditions (Somers et al., 2015; Figure 1C). The ERCC5 gene encodes an endonuclease that cleaves $3^{\prime}$ of DNA adducts and is required for nucleotide excision repair. The mRNA $5^{\prime}$ leader region harbors an uORF. There is a G/A polymorphism, rs751402, located upstream of this $\mathrm{UORF}$ where the A allele containing mRNA has a novel uORF, but the G allele containing mRNA does not. Treatment of cells with cisplatin leads to induction of a stress response,

${ }^{2}$ https://www.ncbi.nlm.nih.gov/projects/SNP/ resulting in phosphorylation of eIF $2 \alpha$ and a longer persistence in translation of the A allele mRNA (Somers et al., 2015). Whereas eIF $2 \alpha$ phosphorylation is generally associated with a global shut down of protein synthesis, the translational output from some mRNAs is paradoxically increased due to the uORF configuration within their $5^{\prime}$ leader regions.

eIF2 is required for ternary complex formation (with tRNA and GTP). When the eIF $2 \alpha$ subunit becomes phosphorylated, ternary complex formation becomes rate-limiting resulting in a global shut down of general translation. Ribosome re-initiation following the translation of an UORF must recruit de novo ternary complexes and increasing the distance of the uORF to the next downstream AUG codon allows more time for that event to take place (Figure 1C). In the case of the ERCC5 A allelecontaining mRNA, the creation of an UORF makes it such that under stress, most ribosomes that have completed translation of the A-encoded uORF will not re-acquire another ternary complex before having scanned past uORF2 (and hence uORF2 won't be translated), but will do so before reaching the ERCC5 ORF (Figure 1C). The creation of new uORFs and their location within the $5^{\prime}$ leader region can thus alter how translation of specific mRNAs respond to signaling cues.

\section{SNPs Affecting an uORF Coding Region}

Mutations arising within the coding region of $\mathrm{uORF}$ have the potential to exert two types of effects on translation - by affecting the nature of an encoded regulatory peptide and by altering elongation rates.

If they perturb the function of a regulatory peptide involved in dictating ribosome re-initiation rates, then they can affect the output from the major ORF. Such might be the case for a G/A SNP in the $5^{\prime}$ leader of the transforming growth factor $\beta 3$ (TGF 33 ) mRNA and present in several members of a large pedigree with arrhythmogenic right ventricular cardiomyopathy type 1 (Beffagna et al., 2005). The TGF 33 mRNA 5' leader contains 11 AUGs potentially encoding 11 polypeptides (Arrick et al., 1991). The G/A SNP does not alter uORF configuration but rather causes an Arg to His substitution at codon 36 of an 88 amino acid uORF that is out of frame and overlaps with the sequence of the TGF $\beta 3$ main AUG. When tested in the context of a luciferase reporter assay in transfected $\mathrm{C} 2 \mathrm{C} 12$ myoblasts cells, the presence of the A variant lead to a 2.5 -fold increase in luciferase production (Beffagna et al., 2005). A similar situation was reported for the serotonin receptor gene, HTR3A, where a C/T SNP located in the second uORF caused a Pro to Ser change in individuals with bipolar affective disorder (Niesler et al., 2001). The authors tested the consequences of this SNP in a luciferase-based transfection assay and found that the $\mathrm{T}$ allele caused a 2.5- to 2.9-fold increase in luciferase expression without altering mRNA levels. One interpretation of these results is that the uORF-encoded peptide plays an inhibitory role in translation and the $G$ to $A$ change impairs activity of this small polypeptide. In both the aforementioned studies, potential effects of the SNP on splicing need to be assessed to rule out other possible explanations for the observed effects.

Alternatively, if variants influence uORF elongation rates then they can influence the potential for re-initiation at downstream 
AUG codons (Jackson et al., 2012; Gunisova et al., 2018). Slowing down elongation rates of ribosomes transiting the $\mathrm{uORF}$ is thought to increase the probability that initiation factors associated with elongating ribosomes, and necessary for elongation, will be released before completion of uORF translation. This would then lead to decreased re-initiation at downstream AUG codons. Conversely, if elongation rates within the $\mathrm{UORF}$ are increased, this might lead to increased re-initiation rates and protein production from downstream ORFs.

\section{5' SNPs AND IRES ACTIVITY}

Another manner by which sequence changes within $5^{\prime}$ leader regions have been documented to alter translation is by affecting IRES activity. The $c-M y c(M Y C)$ proto oncogene has been reported to harbor an IRES which may contribute to translation mis-regulation of MYC during tumorigenesis (Stoneley et al., 1998). Interestingly, a point mutation within the MYC $5^{\prime}$ leader region leading to a $\mathrm{C}$ to $\mathrm{T}$ transition was identified in a multiple myeloma cell line and associated with elevated MYC protein levels (Paulin et al., 1998). The $5^{\prime}$ leader harboring the $\mathrm{T}$ allele showed enhanced binding of several RNA binding proteins, as revealed by Northwestern blotting and UV crosslinking approaches. The same $\mathrm{C}$ to $\mathrm{T}$ mutation was found in $42 \%$ of primary multiple myeloma samples and generated an IRES variant that appeared to be more active (Chappell et al., 2000). The underlying mechanism for how the $\mathrm{C} / \mathrm{T}$ change can lead to alterations in IRES activity awaits further definition.

\section{5' SNPS, TRANSCRIPTION INITIATION SITE SELECTION, AND ALTERNATIVE SPLICING}

Single-nucleotide polymorphisms present within gene regulatory regions can affect transcription factor, as well as RNA Pol II binding (Kasowski et al., 2010). If RNA Pol II binding is redirected to a newly formed site, this could lead to usage of alternative transcription initiation sites - generating mRNAs with differing $5^{\prime}$ leader sequences and which could affect translation initiation rates.

Sequence variation in the $5^{\prime}$ leader region can also occur through alternative mRNA splicing to produce isoforms with different translational efficiency. The presence of SNPs that impact on alternative splicing can change the levels and nature of the resulting mRNA isoforms. For example, thrombopoietin (TPO) is a master regulator of megakaryopoiesis and platelet production and is under tight translational control. Its $5^{\prime}$ leader has seven uORFs (Ghilardi et al., 1998). A SNP has been identified that increases TPO serum levels in patients with hereditary thrombocythaemia (Wiestner et al., 1998), a genetic disorder caused by elevated platelet levels due to sustained proliferation of megakaryocytes (Murphy et al., 1997). Specifically, a G $\rightarrow$ $\mathrm{C}$ transversion at the splicing donor site of TPO intron 3 is responsible for generating a shortened $5^{\prime}$ leader where uORF 7, as well as the main AUG, is lost (Wiestner et al., 1998). Translation initiation thus occurs at the next downstream AUG and leads to a fully functional, although truncated, TPO protein product where levels produced are much higher than from the normal mRNA. This effect appears to be the result of increased translation, presumably through effects on the re-initiation process, since the SNP did not affect RNA levels (Wiestner et al., 1998). Whether SNPs affect splicing or transcription, can only be assessed through sequence characterization of mRNA $5^{\prime}$ leader regions, an analysis that is all too frequently omitted.

\section{5' SNPs AND RNA BINDING PROTEIN TARGET SITES?}

Impacting on RNA binding protein target sites is another manner by which SNPs could affect translation. By measuring the ratio of polysome- to monosome-bound mRNAs in immortalized lymphoblastoid cell lines, a genome-wide search for SNPs affecting translational efficiency was undertaken (Li et al., 2013). This study found that a SNP within the $5^{\prime}$ leader region of the small ribosomal protein S26 mRNA (rs1131017: C/G located 22 nucleotides upstream of the initiator AUG codon) was associated with altered protein production. Reporter mRNAs harboring the $G$ variant produced more protein than mRNAs having the $C$ variant. This SNP is in high linkage disequilibrium with the $12 \mathrm{q} 13$ locus for susceptibility to type I diabetes. It interrupts a polypyrimidine track $\left(. .{ }^{-28}\right.$ TCTCCT $\left.[\mathrm{C} / \mathrm{G}] \mathrm{TCTCC}^{-17} \ldots\right)$ upstream of the rpS26 AUG codon. Whether this alters the binding of an RNA binding protein, such as polypyrimidine tract-binding protein (which has been implicated in translation initiation), remains to be determined (Kaminski and Jackson, 1998).

\section{SNPS AND ELONGATION RATES}

The information contained within mRNAs that encode the proteome is encrypted by 61 possible codons. Codons encoding the same amino acid are decoded by cognate tRNAs, which are not equally expressed in cells. It is generally thought that codon decoding rates can vary as a function of tRNA abundance and this can have dramatic effects on elongation rates (Cannarozzi et al., 2010; Hanson and Coller, 2018). This has been borne out by ribosome footprinting data and by experiments where translational output has been increased simply by replacing rare codons with more frequent ones (Gardin et al., 2014; Lareau et al., 2014; Hussmann et al., 2015; Weinberg et al., 2016). However, rare codons are thought to play important roles in cellular homeostasis since stretches of rare codons induce ribosome pausing during elongation and this provides time for proper protein folding (Hanson and Coller, 2018). Thus, a SNP changing a rare codon to a more common one could, in principle, increase protein output but decrease the proportion of functional (i.e., correctly folded product) polypeptide synthesized.

An example where codon usage could affect protein activity is exemplified by a study assessing the impact of a synonymous SNP (C3435T) present within the multidrug resistance 1 (MDR1) 
coding region on protein function (Kimchi-Sarfaty et al., 2007). The MDR1 gene encodes an ATP-driven drug efflux pump that contributes to drug resistance in tumor cells. The C3435T SNP had been previously associated with reduced MDR1 expression and function in human cells (Hoffmeyer et al., 2000; Drescher et al., 2002). This SNP changes the most common Ile codon (AUC) to a less prevalent one (AUU). Reporter constructs harboring the $\mathrm{C}$ or $\mathrm{T}$ variants show similar protein expression levels, but produce products with different activity (KimchiSarfaty et al., 2007). Trypsin digestion experiments revealed that the MDR1 product from the two different haplotypes differ in their protease sensitivities indicating distinct conformations. Conversion of the Ile codon to an ever rarer one, AUA, generated an mRNA that produced MDR1 protein with even less drug transport activity.

A similar phenomenon was observed for the cystic fibrosis conductance transmembrane regulator (CFTR) gene, in which a T2562G synonymous SNP in the coding region was found to reduce protein levels by $30 \%$ without affecting mRNA levels or splicing (Kirchner et al., 2017). This SNP changed a threonine codon from the highly prevalent ACU sequence to the rarer ACG codon. A CFTR expression vector bearing the $G$ allele showed reduced single-channel $\mathrm{Cl}^{-}$conductance function compared to a T allele expressing vector (Kirchner et al., 2017). The authors concluded that slower synthesis rate from the $G$ allele encoded mRNA resulted in improper protein folding that targeted CFTR for degradation by the quality-control machinery (Kirchner et al., 2017). The reduced protein levels from the $G$ allele mRNA were rescued by transfection of an expression vector driving synthesis of the SNP-corresponding cognate tRNA (Kirchner et al., 2017).

\section{SEQUENCE VARIATION IN 3' UTRS AFFECTING TRANSLATION}

With the exception of histone mRNAs, cellular mRNAs have poly (A) tails at their $3^{\prime}$ end. The poly (A) tail is important for translation initiation and its function is mediated by the poly(A) binding protein, PABPC1. PABPC1 also interacts with eIF4G at the $5^{\prime}$ end of the mRNA to create an mRNA closed loop that is thought to stimulate translation by: (i) stabilizing the association of eIF $4 \mathrm{~F}$ with the cap, (ii) stimulating $60 \mathrm{~S}$ ribosomal subunit binding, and (iii) increasing the effective concentration of terminating ribosomes in proximity of the cap structure. SNPs that mutate the polyadenylation signal will lead to the generation of isoforms with longer $3^{\prime}$ ends due to usage of downstream polyadenylation sites (Thomas and Saetrom, 2012). If the extended sequence results in the acquisition of novel microRNA (miRNAs) binding sites, then regulation of the new mRNA isoform can be quite different than the wild-type mRNA (Sandberg et al., 2008).

As well, mutations that occur within miRNA target sites and alter miRNA recognition can exert effects on mRNA expression through reduced translation initiation and increased mRNA degradation (Mohr and Mott, 2015). The last decade has seen an extensive list of SNPs that map to miRNAs or their putative binding sites within mRNAs that could potentially affect
miRNA response and these have been comprehensively reviewed (Detassis et al., 2017; Moszynska et al., 2017). For example, a G to A SNP has been described in miR-1269, a miRNA linked to increased risks of hepatocellular carcinoma (Min et al., 2017). SPATS2L and LRP6 encode for pro-oncogenic activities and are both targets of miR-1269. This study showed that when the miR1269 A variant is expressed in cells, the repressive effect on SPATS2L and LRP6 is diminished, compared to the miR-1269 $G$ variant. SNPs in microRNA target sites on mRNAs have also been documented. For example, an A to G SNP in the $3^{\prime}$ UTR of TOMM20 mRNA was found to be associated with greater risks of colorectal cancer (Lee et al., 2016). The microRNA miR-4273$5 \mathrm{p}$ was identified as being responsible for controlling the levels of TOMM20.

There are several examples of 3' UTR RNA binding proteins that can affect mRNA translation; both at the initiation and elongation steps (Szostak and Gebauer, 2013; Yamashita and Takeuchi, 2017). The best example is 4EHP (also known as eIF4E2), a cap binding protein known to also interact with specific mRNA-bound proteins present within the mRNA $3^{\prime}$ UTR. 4E-HP thus forms a closed-loop structure and since it does not interact with eIF4G, this prevents ribosomes from being recruited to the cap structure and exerts mRNA-selective inhibition of translation (Morita et al., 2012; Szostak and Gebauer, 2013; Chapat et al., 2017; Yamashita and Takeuchi, 2017). SNPs affecting RNA binding proteins that interact with 4EHP could lead to alterations in expression of a specific set of 4EHP-responsive mRNAs.

\section{CONCLUSION}

Whereas significant effort has been placed on finding and annotating SNPs that can affect protein function using programs such as SIFT (Kumar et al., 2009) and PolyPhen (Adzhubei et al., 2010; Li and Wei, 2015), there is a recognized need for bioinformatics tool that can predict potential functional consequences of SNPs in mRNA $5^{\prime}$ leader and $3^{\prime}$ UTRs (Kumar et al., 2014). Advances have been made (i) regarding software that predicts the effects of SNPs on miRNA targets, with programs such as microSNiPer (Barenboim et al., 2010) and mrSNP (Deveci et al., 2014), (ii) identification of translation initiation sites using ATGpr, and (iii) ORF prediction software such as ORF Finder. What is now needed are tools like SnpEff that could link changes in $5^{\prime}$ leader and $3^{\prime}$ UTR sequences to predictions on major ORF expression. A better understanding of the variables involved in determining mRNA translation efficiency will help design algorithms with more quantitative predictive power.

Much has been learnt from the functional analysis of genetic variants within mRNA $5^{\prime}$ leaders and their effects on translation. The majority of these were identified because they were associated with an observable phenotype. The lesions whose effects are easiest to predict are those affecting initiation codon context or leading to the generation of novel uAUGs. However, it is those whose effects remain unexplained that will likely lead to the uncovering of new biological mechanisms. For example, during 
a search for oncogenic changes associated with prostate cancer, Wang et al. (2009) identified a $G$ to A somatic mutation that mapped within the $\delta$-catenin $5^{\prime}$ leader region, nine nucleotides upstream of the AUG codon. The presence of the A allele in reporter mRNAs resulted in a threefold to sevenfold increase in protein expression relative to mRNAs harboring the $G$ allele, with no effect on mRNA levels noted. The mechanism underlying this translational stimulation is unknown but points to some very interesting biology. It also underscores the need to carefully consider the functional consequence of $5^{\prime}$ leader mutations uncovered by large scale cancer genome sequencing projects and their potential role in affecting translational output. This is currently difficult to do systematically due to deficiencies in our ability to predict RNA structural complexity, as well as a lack of knowledge on the RNA binding protein (RBP) landscape

\section{REFERENCES}

Abastado, J. P., Miller, P. F., Jackson, B. M., and Hinnebusch, A. G. (1991). Suppression of ribosomal reinitiation at upstream open reading frames in amino acid-starved cells forms the basis for GCN4 translational control. Mol. Cell. Biol. 11, 486-496. doi: 10.1128/MCB.11.1.486

Adzhubei, I. A., Schmidt, S., Peshkin, L., Ramensky, V. E., Gerasimova, A., Bork, P., et al. (2010). A method and server for predicting damaging missense mutations. Nat. Methods 7, 248-249. doi: 10.1038/nmeth0410-248

Armata, I. A., Balaj, L., Kuster, J. K., Zhang, X., Tsai, S., Armatas, A. A., et al. (2013). Dopa-responsive dystonia: functional analysis of single nucleotide substitutions within the $5^{\prime}$ untranslated GCH1 region. PLoS One 8:e76975. doi: 10.1371/ journal.pone.0076975

Arrick, B. A., Lee, A. L., Grendell, R. L., and Derynck, R. (1991). Inhibition of translation of transforming growth factor-beta 3 mRNA by its $5^{\prime}$ untranslated region. Mol. Cell. Biol. 11, 4306-4313. doi: 10.1128/MCB.11. 9.4306

Babendure, J. R., Babendure, J. L., Ding, J. H., and Tsien, R. Y. (2006). Control of mammalian translation by mRNA structure near caps. RNA 12, 851-861. doi: 10.1261/rna.2309906

Barbosa, C., Peixeiro, I., and Romao, L. (2013). Gene expression regulation by upstream open reading frames and human disease. PLoS Genet. 9:e1003529. doi: 10.1371/journal.pgen.1003529

Barenboim, M., Zoltick, B. J., Guo, Y., and Weinberger, D. R. (2010). MicroSNiPer: a web tool for prediction of SNP effects on putative microRNA targets. Hum. Mutat. 31, 1223-1232. doi: 10.1002/humu.21349

Beaudoin, J. D., and Perreault, J. P. (2010). 5'-UTR G-quadruplex structures acting as translational repressors. Nucleic Acids Res. 38, 7022-7036. doi: 10.1093/nar/ gkq557

Beffagna, G., Occhi, G., Nava, A., Vitiello, L., Ditadi, A., Basso, C., et al. (2005). Regulatory mutations in transforming growth factor-beta3 gene cause arrhythmogenic right ventricular cardiomyopathy type 1. Cardiovasc. Res. 65 , 366-373. doi: 10.1016/j.cardiores.2004.10.005

Bevilacqua, P. C., Ritchey, L. E., Su, Z., and Assmann, S. M. (2016). Genomewide analysis of RNA secondary structure. Annu. Rev. Genet. 50, 235-266. doi: 10.1146/annurev-genet-120215-035034

Bisogno, L. S., and Keene, J. D. (2018). RNA regulons in cancer and inflammation. Curr. Opin. Genet. Dev. 48, 97-103. doi: 10.1016/j.gde.2017.11.004

Bitterman, P. B., and Polunovsky, V. A. (2015). eIF4E-mediated translational control of cancer incidence. Biochim. Biophys. Acta 1849, 774-780. doi: 10.1016/ j.bbagrm.2014.09.007

Cai, S. P., Eng, B., Francombe, W. H., Olivieri, N. F., Kendall, A. G., Waye, J. S., et al. (1992). Two novel beta-thalassemia mutations in the $5^{\prime}$ and $3^{\prime}$ noncoding regions of the beta-globin gene. Blood 79, 1342-1346.

Calvo, S. E., Pagliarini, D. J., and Mootha, V. K. (2009). Upstream open reading frames cause widespread reduction of protein expression and are polymorphic among humans. Proc. Natl. Acad. Sci. U.S.A. 106, 7507-7512. doi: 10.1073/pnas. 0810916106 in vivo. Genome-wide RNA structure probing approaches, as well as efforts aiming to define the RBP interactome, are being undertaken to fill this void (Castello et al., 2013; Tenzer et al., 2013; Bevilacqua et al., 2016; Bisogno and Keene, 2018).

\section{AUTHOR CONTRIBUTIONS}

All authors drafted and wrote the review.

\section{FUNDING}

Research in the JP's lab is supported by the Canadian Institutes of Health Research (CIHR FDN\#148366).

Cannarozzi, G., Schraudolph, N. N., Faty, M., Von Rohr, P., Friberg, M. T., Roth, A. C., et al. (2010). A role for codon order in translation dynamics. Cell 141, 355-367. doi: 10.1016/j.cell.2010.02.036

Castello, A., Horos, R., Strein, C., Fischer, B., Eichelbaum, K., Steinmetz, L. M., et al. (2013). System-wide identification of RNA-binding proteins by interactome capture. Nat. Protoc. 8, 491-500. doi: 10.1038/nprot.2013.020

Chapat, C., Jafarnejad, S. M., Matta-Camacho, E., Hesketh, G. G., Gelbart, I. A., Attig, J., et al. (2017). Cap-binding protein 4EHP effects translation silencing by microRNAs. Proc. Natl. Acad. Sci. U.S.A. 114, 5425-5430. doi: 10.1073/pnas. 1701488114

Chappell, S. A., Lequesne, J. P., Paulin, F. E., Deschoolmeester, M. L., Stoneley, M., Soutar, R. L., et al. (2000). A mutation in the c-myc-IRES leads to enhanced internal ribosome entry in multiple myeloma: a novel mechanism of oncogene de-regulation. Oncogene 19, 4437-4440. doi: 10.1038/sj.onc.1203791

Cingolani, P., Platts, A., Wang le, L., Coon, M., Nguyen, T., Wang, L., et al. (2012). A program for annotating and predicting the effects of single nucleotide polymorphisms, SnpEff: SNPs in the genome of Drosophila melanogaster strain w1118; iso-2; iso-3. Fly 6, 80-92. doi: 10.4161/fly.19695

Consortium, E. P. (2012). An integrated encyclopedia of DNA elements in the human genome. Nature 489, 57-74. doi: 10.1038/nature11247

Detassis, S., Grasso, M., Del Vescovo, V., and Denti, M. A. (2017). microRNAs make the call in cancer personalized medicine. Front. Cell. Dev. Biol. 5:86. doi: 10.3389/fcell.2017.00086

Deveci, M., Catalyurek, U. V., and Toland, A. E. (2014). mrSNP: software to detect SNP effects on microRNA binding. BMC Bioinformatics 15:73. doi: 10.1186/ 1471-2105-15-73

Diatchenko, L., Slade, G. D., Nackley, A. G., Bhalang, K., Sigurdsson, A., Belfer, I., et al. (2005). Genetic basis for individual variations in pain perception and the development of a chronic pain condition. Hum. Mol. Genet. 14, 135-143. doi: $10.1093 / \mathrm{hmg} / \mathrm{ddi} 013$

Drescher, S., Schaeffeler, E., Hitzl, M., Hofmann, U., Schwab, M., Brinkmann, U., et al. (2002). MDR1 gene polymorphisms and disposition of the P-glycoprotein substrate fexofenadine. Br. J. Clin. Pharmacol. 53, 526-534. doi: 10.1046/j.13652125.2002.01591.x

Gardin, J., Yeasmin, R., Yurovsky, A., Cai, Y., Skiena, S., and Futcher, B. (2014). Measurement of average decoding rates of the 61 sense codons in vivo. eLife 3:e03735. doi: 10.7554/eLife.03735

Ghilardi, N., Wiestner, A., and Skoda, R. C. (1998). Thrombopoietin production is inhibited by a translational mechanism. Blood 92, 4023-4030.

Gunisova, S., Hronova, V., Mohammad, M. P., Hinnebusch, A. G., and Valasek, L. S. (2018). Please do not recycle! Translation reinitiation in microbes and higher eukaryotes. FEMS Microbiol. Rev. 42, 165-192. doi: 10.1093/femsre/ fux059

Hall, J. M., Lee, M. K., Newman, B., Morrow, J. E., Anderson, L. A., Huey, B., et al. (1990). Linkage of early-onset familial breast cancer to chromosome 17q21. Science 250, 1684-1689. doi: 10.1126/science.2270482

Hanson, G., and Coller, J. (2018). Codon optimality, bias and usage in translation and mRNA decay. Nat. Rev. Mol. Cell Biol. 19, 20-30. doi: 10.1038/nrm.2017.91 
Hinnebusch, A. G., Ivanov, I. P., and Sonenberg, N. (2016). Translational control by $5^{\prime}$-untranslated regions of eukaryotic mRNAs. Science 352, 1413-1416. doi: $10.1126 /$ science.aad9868

Hoffmeyer, S., Burk, O., Von Richter, O., Arnold, H. P., Brockmoller, J., Johne, A., et al. (2000). Functional polymorphisms of the human multidrugresistance gene: multiple sequence variations and correlation of one allele with P-glycoprotein expression and activity in vivo. Proc. Natl. Acad. Sci. U.S.A. 97, 3473-3478. doi: 10.1073/pnas.97.7.3473

Holcik, M., and Sonenberg, N. (2005). Translational control in stress and apoptosis. Nat. Rev. Mol. Cell Biol. 6, 318-327. doi: 10.1038/nrm1618

Hussmann, J. A., Patchett, S., Johnson, A., Sawyer, S., and Press, W. H. (2015). Understanding biases in ribosome profiling experiments reveals signatures of translation dynamics in yeast. PLoS Genet. 11:e1005732. doi: 10.1371/journal. pgen.1005732

Jackson, R. J., Hellen, C. U., and Pestova, T. V. (2012). Termination and posttermination events in eukaryotic translation. Adv. Protein Chem. Struct. Biol. 86, 45-93. doi: 10.1016/B978-0-12-386497-0.00002-5

Kaminski, A., and Jackson, R. J. (1998). The polypyrimidine tract binding protein $(\mathrm{PTB})$ requirement for internal initiation of translation of cardiovirus RNAs is conditional rather than absolute. RNA 4, 626-638. doi: 10.1017/ S1355838298971898

Kasowski, M., Grubert, F., Heffelfinger, C., Hariharan, M., Asabere, A., Waszak, S. M., et al. (2010). Variation in transcription factor binding among humans. Science 328, 232-235. doi: 10.1126/science.1183621

Kimchi-Sarfaty, C., Oh, J. M., Kim, I. W., Sauna, Z. E., Calcagno, A. M., Ambudkar, S. V., et al. (2007). A "silent" polymorphism in the MDR1 gene changes substrate specificity. Science 315, 525-528. doi: 10.1126/science.1135308

Kirchner, S., Cai, Z., Rauscher, R., Kastelic, N., Anding, M., Czech, A., et al. (2017). Alteration of protein function by a silent polymorphism linked to tRNA abundance. PLoS Biol. 15:e2000779. doi: 10.1371/journal.pbio.20 00779

Komar, A. A., and Hatzoglou, M. (2015). Exploring internal ribosome entry sites as therapeutic targets. Front. Oncol. 5:233. doi: 10.3389/fonc.2015.00233

Kozak, M. (1986). Point mutations define a sequence flanking the AUG initiator codon that modulates translation by eukaryotic ribosomes. Cell 44, 283-292. doi: 10.1016/0092-8674(86)90762-2

Kozak, M. (1987a). An analysis of $5^{\prime}$-noncoding sequences from 699 vertebrate messenger RNAs. Nucleic Acids Res. 15, 8125-8148.

Kozak, M. (1987b). Effects of intercistronic length on the efficiency of reinitiation by eucaryotic ribosomes. Mol. Cell. Biol. 7, 3438-3445.

Kozak, M. (1991). Structural features in eukaryotic mRNAs that modulate the initiation of translation. J. Biol. Chem. 266, 19867-19870.

Kumar, A., Rajendran, V., Sethumadhavan, R., Shukla, P., Tiwari, S., and Purohit, R. (2014). Computational SNP analysis: current approaches and future prospects. Cell Biochem. Biophys. 68, 233-239. doi: 10.1007/s12013-013-9705-6

Kumar, P., Henikoff, S., and Ng, P. C. (2009). Predicting the effects of coding nonsynonymous variants on protein function using the SIFT algorithm. Nat. Protoc. 4, 1073-1081. doi: 10.1038/nprot.2009.86

Lander, E. S., Linton, L. M., Birren, B., Nusbaum, C., Zody, M. C., Baldwin, J., et al. (2001). Initial sequencing and analysis of the human genome. Nature 409, 860-921. doi: 10.1038/35057062

Lareau, L. F., Hite, D. H., Hogan, G. J., and Brown, P. O. (2014). Distinct stages of the translation elongation cycle revealed by sequencing ribosome-protected mRNA fragments. eLife 3:e01257. doi: 10.7554/eLife.01257

Lee, A. R., Park, J., Jung, K. J., Jee, S. H., and Kim-Yoon, S. (2016). Genetic variation rs7930 in the miR-4273-5p target site is associated with a risk of colorectal cancer. Onco Targets Ther. 9, 6885-6895. doi: 10.2147/OTT.S108787

Li, L., and Wei, D. (2015). Bioinformatics tools for discovery and functional analysis of single nucleotide polymorphisms. Adv. Exp. Med. Biol. 827, 287-310. doi: 10.1007/978-94-017-9245-5_17

Li, Q., Makri, A., Lu, Y., Marchand, L., Grabs, R., Rousseau, M., et al. (2013). Genome-wide search for exonic variants affecting translational efficiency. Nat. Commun. 4:2260. doi: 10.1038/ncomms3260

Liu, L., Dilworth, D., Gao, L., Monzon, J., Summers, A., Lassam, N., et al. (1999). Mutation of the CDKN2A 5' UTR creates an aberrant initiation codon and predisposes to melanoma. Nat. Genet. 21, 128-132. doi: 10.1038/5082

Mailliot, J., and Martin, F. (2018). Viral internal ribosomal entry sites: four classes for one goal. Wiley Interdiscip. Rev. RNA 9:e1458. doi: 10.1002/wrna.1458
Marcotrigiano, J., Lomakin, I. B., Sonenberg, N., Pestova, T. V., Hellen, C. U., and Burley, S. K. (2001). A conserved HEAT domain within eIF4G directs assembly of the translation initiation machinery. Mol. Cell 7, 193-203. doi: 10.1016/S1097-2765(01)00167-8

Mccarroll, S. A., Hadnott, T. N., Perry, G. H., Sabeti, P. C., Zody, M. C., Barrett, J. C., et al. (2006). Common deletion polymorphisms in the human genome. Nat. Genet. 38, 86-92. doi: 10.1038/ng1696

Mendell, J. T., and Dietz, H. C. (2001). When the message goes awry: diseaseproducing mutations that influence mRNA content and performance. Cell 107, 411-414. doi: 10.1016/S0092-8674(01)00583-9

Min, P., Li, W., Zeng, D., Ma, Y., Xu, D., Zheng, W., et al. (2017). A single nucleotide variant in microRNA-1269a promotes the occurrence and process of hepatocellular carcinoma by targeting to oncogenes SPATS2L and LRP6. Bull. Cancer 104, 311-320. doi: 10.1016/j.bulcan.2016. 11.021

Mohr, A. M., and Mott, J. L. (2015). Overview of microRNA biology. Semin. Liver Dis. 35, 3-11. doi: 10.1055/s-0034-1397344

Morita, M., Ler, L. W., Fabian, M. R., Siddiqui, N., Mullin, M., Henderson, V. C., et al. (2012). A novel 4EHP-GIGYF2 translational repressor complex is essential for mammalian development. Mol. Cell. Biol. 32, 3585-3593. doi: 10.1128/MCB. 00455-12

Moszynska, A., Gebert, M., Collawn, J. F., and Bartoszewski, R. (2017). SNPs in microRNA target sites and their potential role in human disease. Open Biol. 7:170019. doi: 10.1098/rsob.170019

Murphy, S., Peterson, P., Iland, H., and Laszlo, J. (1997). Experience of the Polycythemia Vera Study Group with essential thrombocythemia: a final report on diagnostic criteria, survival, and leukemic transition by treatment. Semin. Hematol. 34, 29-39.

Nackley, A. G., Shabalina, S. A., Tchivileva, I. E., Satterfield, K., Korchynskyi, O., Makarov, S. S., et al. (2006). Human catechol-O-methyltransferase haplotypes modulate protein expression by altering mRNA secondary structure. Science 314, 1930-1933. doi: 10.1126/science. 1131262

Nicholson, P., Yepiskoposyan, H., Metze, S., Zamudio Orozco, R., Kleinschmidt, N., and Muhlemann, O. (2010). Nonsense-mediated mRNA decay in human cells: mechanistic insights, functions beyond quality control and the double-life of NMD factors. Cell. Mol. Life Sci. 67, 677-700. doi: 10.1007/s00018-009-0177-1

Niesler, B., Flohr, T., Nothen, M. M., Fischer, C., Rietschel, M., Franzek, E., et al (2001). Association between the $5^{\prime}$ UTR variant C178T of the serotonin receptor gene HTR3A and bipolar affective disorder. Pharmacogenetics 11, 471-475. doi: 10.1097/00008571-200108000-00002

Oner, R., Agarwal, S., Dimovski, A. J., Efremov, G. D., Petkov, G. H., Altay, C., et al. (1991). The G-A mutation at position $+223^{\prime}$ to the Cap site of the betaglobin gene as a possible cause for a beta-thalassemia. Hemoglobin 15, 67-76. doi: 10.3109/03630269109072485

Orlow, I., Begg, C. B., Cotignola, J., Roy, P., Hummer, A. J., Clas, B. A., et al. (2007). CDKN2A germline mutations in individuals with cutaneous malignant melanoma. J. Invest. Dermatol. 127, 1234-1243. doi: 10.1038/sj.jid.57 00689

Orr, N., and Chanock, S. (2008). Common genetic variation and human disease. Adv. Genet. 62, 1-32. doi: 10.1016/S0065-2660(08)00601-9

Paulin, F. E., Chappell, S. A., and Willis, A. E. (1998). A single nucleotide change in the c-myc internal ribosome entry segment leads to enhanced binding of a group of protein factors. Nucleic Acids Res. 26, 3097-3103. doi: 10.1093/nar/26. 13.3097

Pelletier, J., Graff, J., Ruggero, D., and Sonenberg, N. (2015). Targeting the eIF4F translation initiation complex: a critical nexus for cancer development. Cancer Res. 75, 250-263. doi: 10.1158/0008-5472.CAN-14-2789

Pelletier, J., and Sonenberg, N. (1985). Insertion mutagenesis to increase secondary structure within the $5^{\prime}$ noncoding region of a eukaryotic mRNA reduces translational efficiency. Cell 40, 515-526. doi: 10.1016/0092-8674(85)90200-4

Pickering, B. M., and Willis, A. E. (2005). The implications of structured $5^{\prime}$ untranslated regions on translation and disease. Semin. Cell. Dev. Biol. 16, 39-47. doi: 10.1016/j.semcdb.2004.11.006

Poulat, F., Desclozeaux, M., Tuffery, S., Jay, P., Boizet, B., and Berta, P. (1998) Mutation in the $5^{\prime}$ noncoding region of the SRY gene in an XY sexreversed patient. Hum. Mutat. Suppl. 1, S192-S194. doi: 10.1002/humu.13801 10162 
Poyry, T. A., Kaminski, A., and Jackson, R. J. (2004). What determines whether mammalian ribosomes resume scanning after translation of a short upstream open reading frame? Genes Dev. 18, 62-75.

Risch, N. J. (2000). Searching for genetic determinants in the new millennium. Nature 405, 847-856. doi: 10.1038/35015718

Sandberg, R., Neilson, J. R., Sarma, A., Sharp, P. A., and Burge, C. B. (2008). Proliferating cells express mRNAs with shortened $3^{\prime}$ untranslated regions and fewer microRNA target sites. Science 320, 1643-1647. doi: 10.1126/science. 1155390

Schulz, J., Mah, N., Neuenschwander, M., Kischka, T., Ratei, R., Schlag, P. M., et al. (2018). Loss-of-function uORF mutations in human malignancies. Sci. Rep. 8:2395. doi: 10.1038/s41598-018-19201-8

Shen, L. X., Basilion, J. P., and Stanton, V. P. Jr. (1999). Single-nucleotide polymorphisms can cause different structural folds of mRNA. Proc. Natl. Acad. Sci. U.S.A. 96, 7871-7876. doi: 10.1073/pnas.96.14.7871

Signori, E., Bagni, C., Papa, S., Primerano, B., Rinaldi, M., Amaldi, F., et al. (2001). A somatic mutation in the $5^{\prime}$ UTR of BRCA1 gene in sporadic breast cancer causes down-modulation of translation efficiency. Oncogene 20, 4596-4600. doi: $10.1038 /$ sj.onc. 1204620

Somers, J., Wilson, L. A., Kilday, J. P., Horvilleur, E., Cannell, I. G., Poyry, T. A., et al. (2015). A common polymorphism in the $5^{\prime}$ UTR of ERCC5 creates an upstream ORF that confers resistance to platinum-based chemotherapy. Genes Dev. 29, 1891-1896. doi: 10.1101/gad.261867.115

Sonenberg, N., and Hinnebusch, A. G. (2009). Regulation of translation initiation in eukaryotes: mechanisms and biological targets. Cell 136, 731-745. doi: 10. 1016/j.cell.2009.01.042

Srinivasan, S., Clements, J. A., and Batra, J. (2016). Single nucleotide polymorphisms in clinics: fantasy or reality for cancer? Crit. Rev. Clin. Lab. Sci. 53, 29-39. doi: 10.3109/10408363.2015.1075469

Stoneley, M., Paulin, F. E., Le Quesne, J. P., Chappell, S. A., and Willis, A. E. (1998). C-Myc $5^{\prime}$ untranslated region contains an internal ribosome entry segment. Oncogene 16, 423-428. doi: 10.1038/sj.onc.1201763

Szabo, C. I., and King, M. C. (1995). Inherited breast and ovarian cancer. Hum. Mol. Genet. 4, 1811-1817. doi: 10.1093/hmg/4.suppl_1.1811

Szostak, E., and Gebauer, F. (2013). Translational control by $3^{\prime}$-UTR-binding proteins. Brief. Funct. Genomics 12, 58-65. doi: 10.1093/bfgp/els056

Tenzer, S., Moro, A., Kuharev, J., Francis, A. C., Vidalino, L., Provenzani, A., et al. (2013). Proteome-wide characterization of the RNA-binding protein RALY-interactome using the in vivo-biotinylation-pulldown-quant (iBioPQ) approach. J. Proteome Res. 12, 2869-2884. doi: 10.1021/pr400193j

Thomas, L. F., and Saetrom, P. (2012). Single nucleotide polymorphisms can create alternative polyadenylation signals and affect gene expression through loss of
microRNA-regulation. PLoS Comput. Biol. 8:e1002621. doi: 10.1371/journal. pcbi.1002621

Wang, T., Chen, Y. H., Hong, H., Zeng, Y., Zhang, J., Lu, J. P., et al. (2009). Increased nucleotide polymorphic changes in the $5^{\prime}$-untranslated region of delta-catenin (CTNND2) gene in prostate cancer. Oncogene 28, 555-564. doi: 10.1038/onc.2008.399

Weinberg, D. E., Shah, P., Eichhorn, S. W., Hussmann, J. A., Plotkin, J. B., and Bartel, D. P. (2016). Improved ribosome-footprint and mRNA measurements provide insights into dynamics and regulation of yeast translation. Cell Rep. 14, 1787-1799. doi: 10.1016/j.celrep.2016. 01.043

Wiestner, A., Schlemper, R. J., Van Der Maas, A. P., and Skoda, R. C. (1998). An activating splice donor mutation in the thrombopoietin gene causes hereditary thrombocythaemia. Nat. Genet. 18, 49-52. doi: 10.1038/ng 0198-49

Witt, H., Luck, W., Hennies, H. C., Classen, M., Kage, A., Lass, U., et al. (2000). Mutations in the gene encoding the serine protease inhibitor, Kazal type 1 are associated with chronic pancreatitis. Nat. Genet. 25, 213-216. doi: 10.1038/ 76088

Xu, H., Wang, P., You, J., Zheng, Y., Fu, Y., Tang, Q., et al. (2010). Screening of Kozak-motif-located SNPs and analysis of their association with human diseases. Biochem. Biophys. Res. Commun. 392, 89-94. doi: 10.1016/j.bbrc.2010. 01.002

Yamashita, A., and Takeuchi, O. (2017). Translational control of mRNAs by $3^{\prime}$ Untranslated region binding proteins. BMB Rep. 50, 194-200. doi: 10.5483/ BMBRep.2017.50.4.040

Yanagiya, A., Svitkin, Y. V., Shibata, S., Mikami, S., Imataka, H., and Sonenberg, N. (2009). Requirement of RNA binding of mammalian eukaryotic translation initiation factor 4GI (eIF4GI) for efficient interaction of eIF4E with the mRNA cap. Mol. Cell. Biol. 29, 1661-1669. doi: 10.1128/MCB. 01187-08

Conflict of Interest Statement: The authors declare that the research was conducted in the absence of any commercial or financial relationships that could be construed as a potential conflict of interest.

Copyright (c) 2018 Robert and Pelletier. This is an open-access article distributed under the terms of the Creative Commons Attribution License (CC BY). The use, distribution or reproduction in other forums is permitted, provided the original author(s) and the copyright owner(s) are credited and that the original publication in this journal is cited, in accordance with accepted academic practice. No use, distribution or reproduction is permitted which does not comply with these terms. 